\title{
Analisis Web Server untuk Pengembangan Hosting Server Institusi: Pembandingan Kinerja Web Server Apache dengan Nginx
}

\author{
Abdul Aziz, Topan Tampati \\ Jurusan Teknik Informatika dan Komputer \\ Politeknik Negeri Jakarta \\ Jakarta, Indonesia \\ abdul.aziz@tik.pnj.ac.id, topan.tampati@gmail.com
}

Diterima: 12 September 2015. Disetujui: 10 Oktober 2015. Dipublikasikan: November 2015

\begin{abstract}
Abstrak - Proses pertukaran data dan informasi masih terhambat dikarenakan belum terpusatnya sumber informasi dan data yang dibutuhkan Jurusan Teknik Informatika dan Komputer Politeknik Negeri Jakarta. Oleh karena itu dibutuhkan sebuah komputer server sebagai wadah dari web server yang dapat dimanfaatkan bagi pengguna individu maupun pengguna kelompok. Dengan perkembangan internet dan pengguna website semakin besar serta salah satu alasan memberikan cara yang mudah dan cepat dalam mengirimkan data dan informasi. Web server memenuhi kebutuhan untuk menopang website, email, dan lain-lain, serta untuk mempercepat dan mengorganisasi informasi dan data secara terpusat yang kemudian diimplementasikan pada jaringan enterprise Jurusan Teknik Informatika dan Komputer Politeknik Negeri Jakarta. Kinerja dari web server Apache dan Nginx untuk mengetahui manakah yang lebih unggul dari kedua web server tersebut. Metode yang digunakan adalah studi literatur mengenai web server, diskusi dan pengamatan upaya untuk menentukan software yang paling tepat digunakan untuk web server, dan pengujian. Dari tahapan yang dilakukan dapat disimpulkan bahwa web server dangan menggunakan Apache lebih unggul dibandingkan dengan web server yang menggunakan Nginx, kinerja Apache dalam transfer data, Connection, dan request data lebih baik sehingga memudahkan client dalam mendapatkan informasi yang dibutuhkan. Dengan kelebihan kecepatan transfer rata-rata $701 \mathrm{Kbytes} / \mathrm{sec}$, web server Apache dapat diimplementasikan di jaringan enterprise Jurusan Teknik Informatika dan Komputer Politeknik Negeri Jakarta.
\end{abstract}

Kata Kunci: data, informasi, jaringan enterprise, web server, apache, nginx, transfer data, connection, request data.

\section{PENDAHULUAN}

Seorang pengguna pada suatu institusi melakukan penyimpanan data selalu pada komputernya masing-masing atau sistem penyimpanan secara personal. Sehingga saat ingin melakukan pertukaran data diperlukan komputer atau perangkat memori penyimpan data yang terpisah, dan dengan demikian pengguna tersebut adalah seorang yang memiliki akses pada komputer dan memori terpisah agar dapat membuka dan mengakses. Tentunya ini akan membuat pihak yang terkait harus memberikan tenaga dan waktu yang lebih saat akan melakukan pertukaran data. Dan bagaimana jika kejadian tersebut dilakukan oleh beberapa orang pada suatu institusi. Insiden tersebut merupakan gambaran suatu kebutuhan akan sebuah komputer server yang dapat menunjang dan mendukung kinerja dari sistem pertukaran data dan informasi, antara lain dengan menggunakan sistem hosting server yang di dalamnya mencakup database server yang dapat menampung semua file yang diperlukan oleh institusi untuk bertukar data dan informasi.

Hosting server adalah salah satu solusi untuk permasalahan tersebut, karena pada hosting control panel memungkinkan untuk mengelola beberapa server seperti web server dan mail server serta beberapa fitur tambahan seperti DNS dan file transfer. Hosting server dapat mempermudah dalam mengolah penggunaan server seperti penambahan user untuk mail server. Pada hosting sever ini akan mempermudah pengguna mendapatkan informasi yang dibutuhkan, salah satunya melalui website. Dimana website digunakan banyak orang untuk memuat informasi yang dibutuhkan, sehingga mempermudah dalam pertukaran informasi. Teknologi website tidak terlepas dengan data penyimpanan, atau wadah dimana website tersebut disimpan. Website tersimpan dalam web server yang menunjang dan mendukung kinerja dari website [1].

Perangkat lunak web server dikenal dapat melayani permintaan pengguna berupa http dari client yang terhubung dalam jaringan dan 
memberikan pelayanan kepada yang meminta informasi berkaitan dengan website dan memberikan suatu hasil berupa halaman web yang ditampilkan dalam browser. Web server menggunakan port 80 , web server sendiri terdiri dari dua komponen, yang pertama adalah komputer dan software web server yang digunakan [2]. Dimana pada web server inilah website yang digunakan untuk memberikan informasi atau bertukar informasi ditempatkan. Aplikasi web server dapat diperoleh dengan mudah baik yang berbayar maupun tanpa bayar. Saat akan memilih perangkat lunak aplikasi web server, administrator web harus memilih web server manakah yang akan digunakan untuk melayani para pengguna website institusinya, administrator melakukan ini ketika akan melakukan hosting server untuk digunakan website institusi.

Berkaitan dengan pelayanan server, membutuhkan aplikasi pada sistem komputer (computer server dedicated) yang berfungsi melayani permintaan akses dari komputer pengguna. Beberapa aplikasi pelayanan server antara lain $W e b$ Server, FTP Server, DHCP Server, Mail Server, DNS Server, FTP Server, dan Database Server [3]. Bila web server dan website-nya yang berisi tampilan informasi-informasi dapat diakses menggunakan web browser seperti Mozilla Firefox atau Google Chrome.

Berikut merupakan jenis web server antara lain: Apache Web Server, Apache Tomcat, MS Windows server 2003 Internet Information Service (IIS), Light HTTP, Sun Java System Web Server, Zerus Web Server serta Nginx. Studi implementasi hosting server, khusus fokus pada bagian implementasi web server akan bertemu pada masalah bagaimana kinerja web server itu sendiri. Dan studi kinerja dari web server pada permasalahan menganalisis kinerja web server yang akan diimplementasi. Studi web server akan bertemu dengan berbagai aplikasi perangkat lunak web server seperti tersebut di atas. Analisis mengangkat pembandingan web server Apache dengan web server Nginx.

Beberapa hal dasar yang perlu diketahui berkaitan dengan pembandingan aplikasi web server yang dianalisis. Hosting Server, Apache HTTP server, web server Nginx, dan hasil studi pembandingan yang telah dilakukan beberapa peneliti lainnya, studi pembandingan kinerja web server menjadi menarik. Kontribusi analisis web server untuk pengembangan hosting server institusi, khusus fokus pada bagian implementasi web server yang bertemu pada masalah bagaimana kinerja web server, berujung pada pembandingan kinerja web server: 1) Memberikan alternatif pemilihan web server yang dapat melayani kecepatan transfer data, waktu request, dan koneksi, 2) Memberikan solusi bagi administrator untuk menentukan topologi jaringan. Dan terakhir, gambaran dan penyesuaian penggunaan web server dilihat dari kelebihan dan kekurangannya akan diperoleh administrator.

Hosting server merupakan komputer khusus yang terhubung dengan internet secara real time, dan secara terus-menerus agar pengguna internet dapat mengakses perangkat lunak yang menjadi backbone dari World Wide Web dikenal dengan web server merupakan perangkat lunak server [3]. Web server, merupakan perangkat lunak untuk berkomunikasi dengan client (web browser) dan mempunyai protokol sendiri yaitu Hyper Text Transfer Protocol [4]. Dengan protokol ini, komunikasi antar web server dengan client-nya (browser) dapat saling dimengerti dan lebih mudah. Proses yang dimulai dari permintaan client (browser), diterima web server, diproses, dan dikembalikan hasil prosesnya oleh web server ke web client lagi dilakukan secara transparan [5]. HTTPS memiliki pengertian yang sama dengan HTTP hanya saja HTTPS memiliki fungsi di bidang keamanan (secure). HTTPS menggunakan Secure Socket Layer (SSL) atau Transport Layer Security (TLS) sebagai sub layer dibawah HTTP aplikasi layer [6].

HTTP di-enkripsi dan deskripsi dari halaman yang diminta oleh pengguna dan halaman yang dikembalikan oleh web server. Kedua protokol tersebut memberikan perlindungan yang memadai dari serangan eaves droppers dan man in the middle attacks. Pada umumnya port yang digunakan HTTPS adalah port 443. Tingkat keamanan tergantung pada ketepatan dan mengimplementasikan pada browser dan perangkat lunak server dan didukung oleh algoritma penyandian yang aktual. Oleh karena itu, pada halaman web digunakan HTTPS dan URL yang digunakan dimulai dengan https:// [7].

Apache HTTP server adalah perangkat lunak dengan platform oprating system (OS) yang mendukung multi-tasking, dan menyediakan layanan untuk aplikasi lain yang terhubung ke dalamnya, seperti web browser. Apache pertama kali dikembangkan untuk bekerja dengan sistem operasi Linux/Unix, tetapi kemudian diadaptasi untuk bekerja di bawah sistem lain, termasuk Windows dan Mac [4].

Nginx adalah software open-source yang memiliki kinerja tinggi sebagai server HTTP dan reverse proxy. Nginx dengan cepat memberikan konten statis dengan penggunaan efisien sumber daya sistem. Hal ini dapat menyebarkan dinamis HTTP konten di jaringan menggunakan FastCGI handler untuk script, dan dapat berfungsi sebagai perangkat lunak yang sangat mampu penyeimbang beban. Nginx dibangun secara modular dan dengan demikian mampu mendukung berbagai fitur seperti Load Balancing dan Reverse Proxying, Virtual hosts 
berbasis nama dan IP, Fast CGI, akses langsung ke cache, SSL, Flash Video Streaming dan sejumlah fitur-fitur standar lainnya. Nginx dapat dijalankan dan tersedia untuk platform Unix, Linux, varian dari BSD, MacOS X, Solaris, dan Microsoft Windows [8].

Nginx menjadi pilihan berkat kinerjanya yang tinggi, stabilitas, kekayaan akan fitur, mudah dikonfigurasi dan terutama hemat sumber daya [9]. Berbeda dengan server tradisional, Nginx tidak sepenuhnya bergantung pada 'thread' untuk menangani permintaan (request). Sebagai pengganti Nginx menggunakan teknik arsitektur yang digerakkan berdasarkan event yang lebih skalabel (scalable asynchronous event-driven architectur). Arsitektur ini ternyata pada saat dibebani hanya memerlukan sedikit memori dalam jumlah yang bisa diprediksikan.

Awalnya Nginx dibangun di Rusia untuk memenuhi kebutuhan mesin pencari skala besar Ramble yang tetap memanfaatkannya sampai sekarang. Berkat berbagai kemampuan yang dimilikinya, termasuk kinerja yang tinggi dan fleksibilitas dalam konfigurasi, Nginx banyak digunakan untuk mendukung layanan web skala besar antara lain WordPress.com, SourceForge, Hulu, ComputerBase [8];[10]. Nginx menggunakan pendekatan asynchronous-event untuk menangani permintaan yang diprediksi memberikan kinerja yang lebih bawah beban, kontras dengan Apache HTTP server [11];[8]. Fitur yang lain: Handling of static files, index files, and autoindexing, Reverse proxy with caching, Load balancing, Fault tolerance, Web page access authentication, gzip compression, Ability to handle more than 10000 simultaneous connections, URL rewriting, Custom logging, Server-side includes. Fitur Mail proxy: SMTP, POP3, and IMAP proxy, STARTTLS dan STLS support, SSL http [8].

DNS (Domain Name System), sebuah sistem yang menyimpan informasi tentang nama host maupun nama domain dalam bentuk basis data tersebar (distributed database) di dalam jaringan komputer, misalkan internet. Fungsi utama dari sebuah sistem DNS adalah menerjemahkan namanama host (hostnames) menjadi nomor IP (IP address) ataupun sebaliknya, sehingga nama tersebut mudah diingat oleh pengguna internet [5]. Fungsi lainnya adalah untuk memberikan suatu informasi tentang suatu host ke seluruh jaringan internet.

Beberapa hasil penelitian berkaitan web server Apache dan Nginx melaporkan, bahwa Nginx + php-fpm jauh lebih baik daripada Apache + mod_php5. "Jauh lebih baik" didefinisikan sebagai hasil akhir di mana Nginx bisa melayani jumlah http request jauh lebih banyak daripada Apache. Kemudian penelitian lain bahwa php fpm yang listen di tcp socket performa kerjanya lebih buruk daripada apabila dijalankan di Unix socket [11]. Percobaan tersebut dibangun menggunakan PHP dengan database PostgreSQL. Kerja script mengambil beberapa ratus record dari database, kemudian mengirimkan hasil html ke browser. Lokasi database terpisah dari server web. Server web yang digunakan punya RAM 4GB, harddisk SAS 15k 136GB, dan 8 processor cores. Php-fpm berjalan menggunakan Unix socket.

Konfigurasi Apache dan Nginx standar, hanya mengubah timeout untuk keep alive menjadi 3 detik. OS server yang digunakan adalah Ubuntu 12.04 tanpa custom repo. Tes beban dilakukan dengan menggunakan Siege atau Apache benchmark (ab), prinsipnya sama saja. Hasil analisis Apache vs Nginx adalah perbedaan konsumsi RAM. Pada percobaan (-c 150), Apache bisa memakai memory RAM hingga $715 \mathrm{MB}$, sedangkan menggunakan RAM hingga 575MB. Selisih sekitar 24\%. Untuk $w e b$ yang ditempatkan di VPS dengan RAM kecil boleh jadi ini ada bedanya. Perbedaan lain adalah kecepatan turunnya penggunaan RAM setelah tes. Tampaknya Nginx melepas RAM lebih cepat daripada apache. Dan menjelaskan Nginx tidak memakan RAM sebanyak Apache; Performa keduanya dianggap sama, beda pun sangat tipis; Pada jumlah concurrency tinggi (-c 350), php-fpm dengan tcp socket bisa lebih stabil daripada menggunakan Unix socket [11].

Hasil penelitian yang telah dipaparkan di atas menunjukkan hasil perbandingan web server Apache dengan Nginx pada pengukuran tes kinerja menggunakan PHP dengan database PostgreSQL. Kerja script mengambil beberapa ratus record dari database, kemudian mengirimkan hasil HTML ke browser, dimana lokasi database terpisah dari server web.

\section{METODE PENELITIAN PENGEMBANGAN HOSTING SERVER}

Pada metode penelitian kami dengan menggunakan dua web server yang sama yaitu Apache dan Nginx, kedua web server ini ditujukan untuk wadah dari http yang cenderung kepada website dan email. Pengujian yang dilakukan adalah menguji performa kecepatan kedua web server untuk mengetahui kinerja masing-masing. Pengujian ini lebih kepada masalah cepat waktu yang digunakan untuk mengakses sebuah web. Manakah web server yang lebih efektif dalam meng-handle setiap aktifitas yang dilakukan oleh $u$ ser secara bersamaan. Kemudian dijabarkan bagaimana melakukan pengujian ini, setelah itu berlanjut pada hasil pengujian. Dan melakukan analisis kinerja web server Apache dan Nginx. 


\section{A. Kebutuhan Perangkat Keras dan Perangkat Lunak}

Analisis hosting server sistem operasi yang digunakan Linux, Ubuntu. Ubuntu termasuk sistem operasi open source dan free software dan sistem operasi server yang stabil. Perangkat lunak hosting server yang akan diimplementasikan pada institusi perangkat lunak adalah web server, database server, DNS server, email server, file transfer. Server basis data yang akan dibangun pada hosting server infrastruktur institusi adalah server basis data MySQL server dan PostgreSQL server. Sebagai perangkat lunak untuk analisis pengembangan web server basis data, MySQL server dan PostgreSQL server memiliki kelebihan dan kekurangan masingmasing. Pada bagian lain penelitian pengembangan web server institusi, kedua perangkat lunak ini diperbandingkan untuk mengetahui perangkat lunak sistem database server mana yang lebih tangguh dan lebih baik.

Selanjutnya perangkat lunak DNS server yang memiliki fungsi khusus yang digunakan sebagai master DNS server sehingga dalam proses konfigurasi dan penggunaannya lebih mudah. Dan mendukung penyimpanan data DNS dengan menggunakan basis data sehingga memudahkan dalam pengelolahan nama domain dan replikasi data DNS, spesifikasi tersebut antara lain dimiliki oleh Power DNS. Sedangkan untuk slave DNS, menggunakan Bind atau bisa disebut dengan penyimpanan kedua (secondary) yang mana data yang ada dalam Power DNS langsung tersingkronkan pada Bind sehingga ketika salah satu dari software DNS mati maka software yang lainnya yang akan membackupnya.

Email server menggunakan webmail roundcube dengan protokol IMAP dan Microsoft Outlook dengan protokol POP3. IMAP memungkinkan pengguna memilih pesan yang akan diambil, membuat folder di server, mencari pesan tertentu, maupun menghapus pesan yang ada dan terjadi komunikasi dua arah, sehingga terjadi sinkronisasi data. Sedangkan POP3 yang hanya memperbolehkan kita mengambil atau download semua pesan yang ada tanpa kecuali dan hanya bekerja dengan satu arah saja.

File transfer dibutuhkan software protokol SFTP dan FTP. SFTP dan FTP adalah suatu protokol dengan persamaan dapat tukar-menukar file dalam suatu network yang men-support TCP/IP. Terdapat dua hal penting agar terjalinnya komunikasi data yaitu adanya sisi server dan client. Fungsi utama aplikasi ini adalah untuk mengakses mesin secara remote. Bentuk akses remote yang bisa diperoleh adalah akses pada mode teks maupun mode grafis/X apabila konfigurasinya mengizinkan.

\section{B. Rencana Pelaksanaan Pengujian dan Analisis}

Gambar 1 adalah diagram blok kerja alat, merupakan dinamika kerja sistem perangkat lunak pada hosting server, merupakan blok diagram pelaksanaan pengujian.

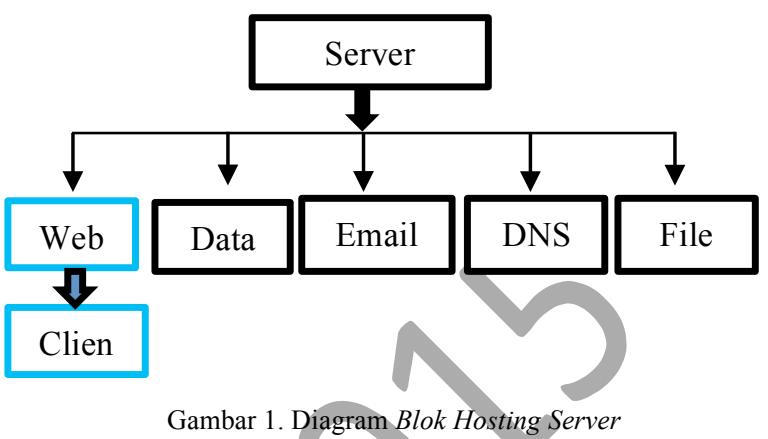

Blok diagram di atas percobaan web server yang diimplementasikan pada hosting server menggunakan program dengan software open source dan akan berjalan diatas sistem operasi Ubuntu. Cara kerja web server terhubung dengan server, email server, database server, DNS server, serta file transfer untuk upload dan download berkas-berkas yang berada didalam server. Web server yang berkerja sebagai backbone dari World Wide Web. Web server digunakan untuk berkomunikasi dengan client-nya (web browser). Pelaksanaan pengujian dan menganalisis untuk pengembangan hosting server institusi menggunakan perangkat keras dan perangkat lunak dengan spesifikasi perangkat keras server merupakan komponen server komputer berfungsi operasional, penyimpan, dan proses sistem dengan spesifikasi seperti pada Tabel 1. Sedangkan spesifikasi perangkat lunak hosting server, dibutuhkan software seperti Sistem Operasi Linux Ubuntu version 14 dengan aplikasi didalamnya seperti :

1. Web Server : Apache, Nginx, dan PHP5

2. Database Server: Mysql dan PostgreSQL

3. DNS Server : Power DNS dan Bind

4. Email Server : Postfix, Roundcube, dan MS Outlook

5. File Transfer : SFTP dan FTP

\section{PENGUJIAN DAN ANALISIS DATA}

Pengujian dilakukan pada pengujian kecepatan akses layanan kedua web server melalui Ubuntu server, mulai dari waktu request, waktu transfer, dan waktu koneksi. Dan dengan menggunakan 5 sample pengaksesan halaman website yang akan diuji pada kedua web server tersebut. 
A. Prosedur dan pelaksanaan pengujian

1. Membuka putty untuk me-remote server, lalu melakukan login pada ubuntu server dengan account yang telah dibuat sebelumnya, pastikan berada dalam user "root" ketika menjalankan Ubuntu server.

2. Setelah masuk kedalam ubuntu server, dilanjutkan dengan melakukan pengujian dengan waktu pengujian setiap web server dan http yang akan diujikan selama 60 second atau 1 menit dengan request pengaksesan secara bersamaan yaitu 10 koneksi. Pertama pengujian untuk web server Apache pada Ubuntu server dengan menggunakan perintah yang dijalankan pada terminal Ubuntu server "ab -c 10 -t60 http:// ip.domain/xxxx/xxx.php". Dimana "ab" ini adalah sebuah utilities untuk membaca script benchmark, c 10 adalah request secara bersamaan dalam satu waktu, dan t60 adalah lama waktu yang digunakan dan selanjutnya adalah file atau target yang ingin di uji. Perintah benchmark untuk web server apache yang diuji dengan akses alamat web index.php dan perintah benchmark untuk web server Nginx dengan akses alamat web yang serupa yaitu index.php. Dan mendapatkan hasil benchmark. Hasil ini menjelaskan tentang rentang waktu yang digunakan untuk akses request, transfer, dan koneksi. Hasil pengujian dari halaman index pertama dari kedua web server dari benchmark apache server untuk halaman web index yang menggunakan waktu tes 60 second mendapatkan hasil seperti :

- Time per request: 394.955 (ms)

- Transfer rate: 948.61 (Kbytes/sec)

- Connection Times: 393 (ms)

Hasil pengujian berikut dari benchmark Nginx server untuk halaman web index yang menggunakan waktu tes 60 second mendapatkan hasil seperti :

- Time per request

- Transfer rate $516.168(\mathrm{~ms})$

- Connection Times 719.75 (Kbytes/sec) : $513(\mathrm{~ms})$

3. Selanjutnya pengujian dengan mengakses halaman web yang lain dengan metode yang sama seperti halaman index sebelumnya. Halaman web yang akan diuji dengan kedua web server ini yaitu administrator dari website

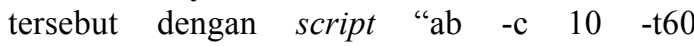
http://172.16.0.XX/

prestashop/adminXXXX/index.php?controller=A dminLogin". Hasil yang didapat dari pengujian pertama untuk server Nginx. Hasil dari benchmark Apache server untuk halaman web admin login yang menggunakan waktu tes 60 second mendapatkan hasil seperti :

- Time per request : 102.725 (ms)

- Transfer rate : 60.28 (Kbytes/sec)

- Connection Times : 103 (ms)

Hasil dari benchmark Nginx server untuk halaman web admin login yang menggunakan waktu tes 60 second mendapatkan hasil seperti :

- Time per request : 148.332 (ms)

- Transfer rate : 40.09 (Kbytes/sec)

- Connection Times : 148 (ms)

4. Selanjutnya pengujian dengan mengakses halaman web category yang terdapat pada website yang akan diuji oleh kedua web server yang digunakan. Script yang digunakan untuk mengeksekusi halaman web tersebut yaitu "ab -c $10 \quad-t 60 \quad$ http://172.16.0.XX/prestashop/ index.php?id_category $=5$ “. Hasil yang didapat dari pengujian pertama halaman web category dijabarkan. Hasil dari benchmark Apache server untuk halaman web category yang menggunakan waktu tes 60 second mendapatkan hasil seperti :
- Time per request : 482.511 (ms)
- Transfer rate : 773.83 (Kbytes/sec)
Connection Times : 479 (ms)

Hasil dari benchmark Nginx server untuk halaman web category yang menggunakan waktu tes 60 second mendapatkan hasil seperti :

- Time per request : 649.507 (ms)

- Transfer rate : 573.27 (Kbytes/sec)

- Connection Times : 648 (ms)

5. Pengujian halaman website yang keempat yaitu authentication account yang terdapat pada website yang diakses. Kedua web server menguji halaman web authentication dengan perintah script yang digunakan pada Ubuntu server yaitu "ab $-\mathrm{c} \quad 10 \quad-\mathrm{t} 60$ http:// 172.16.0.xx/prestashop/index.php?controller $=\mathrm{au}$ tentication. Hasil dari pengujian pertama authentication account. Hasil dari benchmark apache server untuk halaman web authentication yang menggunakan waktu tes 60 second mendapatkan hasil seperti :

- Time per request : $474.366(\mathrm{~ms})$

- Transfer rate : 771.70 (Kbytes/sec)

- Connection Times : 472 (ms)

Hasil dari benchmark Nginx server untuk halaman web authentication yang menggunakan waktu tes 60 second mendapatkan hasil seperti :

- Time per request : $675.777(\mathrm{~ms})$

- Transfer rate : 539.91 (Kbytes/sec)

- Connection Times : 672 (ms)

6. Pengujian terakhir untuk kedua web server yaitu dengan pengaksesan halaman web price atau 
diskon yang masih menggunakan metode yang sama yaitu dengan lama waktu yang digunakan yaitu 60 second dengan 10 koneksi pengaksesan secara bersamaan. Script yang digunakan pada Ubuntu server untuk pengujian terakhir yaitu "ab -c 10 -t60 http://172.16.0.XX/prestashop/ index.php? controller=prices-drop“. Hasil dari pengujian pertama dari halaman terakhir yaitu pada halaman web price atau diskon ini ditampilkan untuk web server Apache dan pada web server Nginx. Hasil dari pengujian benchmark Apache server untuk halaman web terakhir yaitu price yang menggunakan waktu tes 60 second mendapatkan hasil seperti :
- Time per request
: $565.559(\mathrm{~ms})$
- Transfer rate
: 659.82 (Kbytes/sec)
- Connection Times : $564(\mathrm{~ms})$

Hasil dari pengujian benchmark Nginx server untuk halaman web terakhir yaitu price yang menggunakan waktu tes 60 second mendapatkan hasil seperti :

- Time per request : $727.601(\mathrm{~ms})$

- Transfer rate : 509.76 (Kbytes/sec)

- Connection Times : 725 (ms)

\section{B. Data Hasil pengujian}

Dari hasil pengujian yang telah dilakukan sebelumnya antara web server Apache dan web server Nginx yang diuji menggunakan ubuntu server, dengan waktu pengujian selama 60 second dan 10 request koneksi secara bersamaan dan pelaksanaan pengujian dilakukan 3 kali percobaan untuk setiap halamannya, maka didapatkan hasil seperti Tabel 1 - Tabel 5. Hasil didapatkan menggunakan pembulatan angka, jika di belakang koma muncul angka 1-5 maka dijadikan 0, sedang angka 6-9 dijadikan 1.

Hasil pengujian halaman index:

TABEL 1. PENGUJIAN HALAMAN INDEX

\begin{tabular}{|c|c|c|c|c|}
\hline $\mathrm{N}$ & Variable & obaan & $\begin{array}{c}\text { Percobaan } \\
2\end{array}$ & Percobaan 3 \\
\hline 1 & $\begin{array}{l}\text { Time per } \\
\text { Request } \\
\text { on Apache }\end{array}$ & $\begin{array}{l}394.955= \\
395(\mathrm{~ms})\end{array}$ & $\begin{array}{l}565.654= \\
566(\mathrm{~ms})\end{array}$ & $\begin{array}{c}504.702= \\
504(\mathrm{~ms})\end{array}$ \\
\hline 2 & $\begin{array}{l}\text { Time per } \\
\text { Request } \\
\text { on Nginx }\end{array}$ & $\begin{array}{l}516.168= \\
516(\mathrm{~ms})\end{array}$ & $\begin{array}{l}754.924= \\
755(\mathrm{~ms})\end{array}$ & $\begin{array}{c}694.492= \\
694(\mathrm{~ms})\end{array}$ \\
\hline 3 & $\begin{array}{l}\text { Connectio } \\
n \quad \text { Times } \\
\text { on Apache }\end{array}$ & $393(\mathrm{~ms})$ & $562(\mathrm{~ms})$ & $500(\mathrm{~ms})$ \\
\hline 4 & $\begin{array}{l}\text { Connectio } \\
n \quad \text { Times } \\
\text { on Nginx }\end{array}$ & $513(\mathrm{~ms})$ & 749 (ms) & $691(\mathrm{~ms})$ \\
\hline 5 & $\begin{array}{l}\text { Transfer } \\
\text { Rate on } \\
\text { Apache }\end{array}$ & $\begin{array}{l}948.61= \\
949 \\
(\text { Kbyetes } / \text { s) }\end{array}$ & $\begin{array}{l}659.14= \\
659 \\
\text { (Kbyetes } / \text { s) }\end{array}$ & $\begin{array}{c}743.70= \\
744 \\
\text { (Kbyetes } / \text { s) }\end{array}$ \\
\hline 6 & $\begin{array}{l}\text { Transfer } \\
\text { Rate on } \\
\text { Nginx }\end{array}$ & $\begin{array}{l}719.75= \\
720 \\
(\text { Kbyetes } / \text { s) }\end{array}$ & $\begin{array}{l}492.09= \\
492 \\
(\text { Kbyetes } / \text { s) }\end{array}$ & $\begin{array}{c}535.05= \\
535 \\
(\text { Kbyetes } / \text { s) }\end{array}$ \\
\hline
\end{tabular}

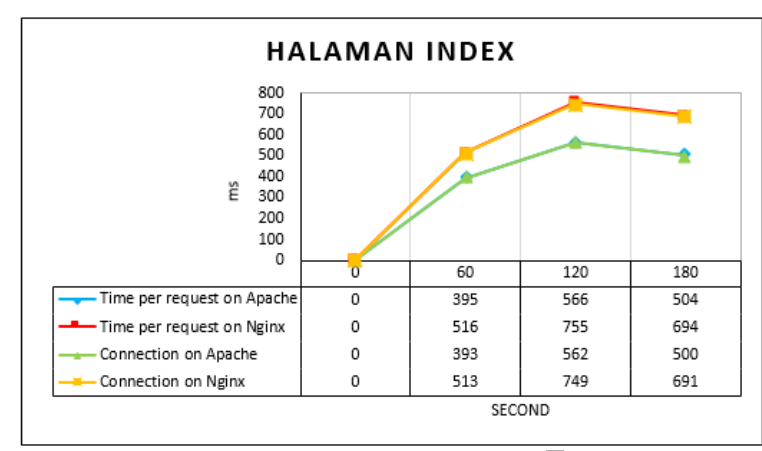

Gambar 2. Grafik Pengujian Halaman Index

Pada Gambar 2 menjelaskan grafik dari hasil pengujian yang dilakukan pada halaman index untuk setiap variabelnya dari 60 second pertama sampe 60 second ketiga.

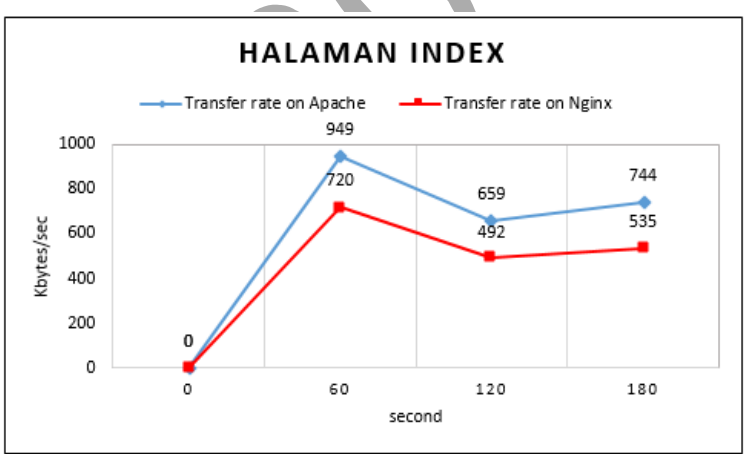

Gambar 3. Grafik Pengujian Halaman Index - Transfer Rate

Pada Gambar 3 menjelaskan grafik dari hasil pengujian transfer rate yang didapat dari halaman index. Hasil pengujian halaman admin login I seperti pada Tabel 2.

TABEL 2. PENGUJIAN HALAMAN ADMIN LOGIN

\begin{tabular}{|c|c|c|c|c|}
\hline No & Variable & Percobaan 1 & Percobaan 2 & $\begin{array}{c}\text { Percobaan } \\
3\end{array}$ \\
\hline 1 & $\begin{array}{c}\text { Time per } \\
\text { Request on } \\
\text { Apache }\end{array}$ & $\begin{array}{c}136.911= \\
137(\mathrm{~ms})\end{array}$ & $\begin{array}{c}163.195= \\
163(\mathrm{~ms})\end{array}$ & $\begin{array}{c}128.833= \\
129(\mathrm{~ms})\end{array}$ \\
\hline 2 & $\begin{array}{l}\text { Time per } \\
\text { Request on } \\
\text { Nginx } \\
\end{array}$ & $\begin{array}{c}179.976= \\
180(\mathrm{~ms})\end{array}$ & $\begin{array}{c}205.421= \\
205(\mathrm{~ms})\end{array}$ & $\begin{array}{c}164.302= \\
164(\mathrm{~ms})\end{array}$ \\
\hline 3 & $\begin{array}{c}\text { Connection } \\
\text { Times on } \\
\text { Apache }\end{array}$ & $137(\mathrm{~ms})$ & $163(\mathrm{~ms})$ & 129 (ms) \\
\hline 4 & $\begin{array}{c}\text { Connection } \\
\text { Times on } \\
\text { Nginx }\end{array}$ & $180(\mathrm{~ms})$ & $205(\mathrm{~ms})$ & 164 (ms) \\
\hline 5 & $\begin{array}{l}\text { Transfer } \\
\text { Rate on } \\
\text { Apache }\end{array}$ & $\begin{array}{c}353.63=354 \\
(\text { Kbyetes } / s)\end{array}$ & $\begin{array}{c}296.75 \\
=297 \\
\text { (Kbyetes } / \text { s) }\end{array}$ & $\begin{array}{c}375.80 \\
=376 \\
\text { (Kbyetes } / \text { s) }\end{array}$ \\
\hline 6 & $\begin{array}{l}\text { Transfer } \\
\text { Rate on } \\
\text { Nginx }\end{array}$ & $\begin{array}{c}268.12=268 \\
(\text { Kbyetes } / s)\end{array}$ & $\begin{array}{c}235.01 \\
=235 \\
\text { (Kbyetes } / \text { s) }\end{array}$ & $\begin{array}{c}293.61 \\
=294 \\
\text { (Kbyetes } / \text { s) } \\
\end{array}$ \\
\hline
\end{tabular}




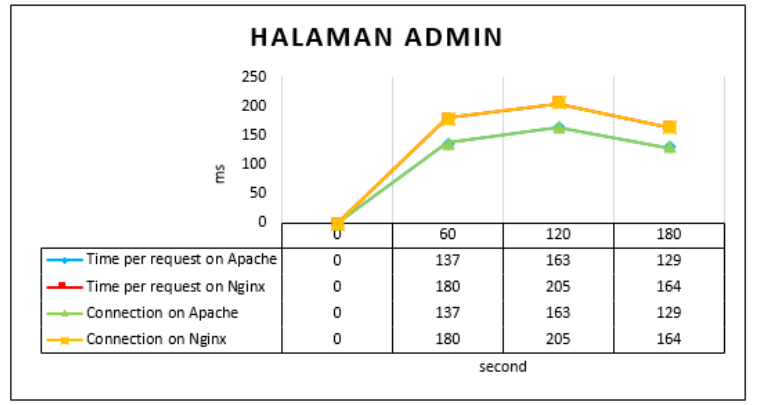

Gambar 4. Grafik Pengujian Halaman Admin Login

Pada Gambar 4 grafik yang dihasilkan dari pengujian halaman admin yang dilakukan sebanyak 3 kali percobaan.

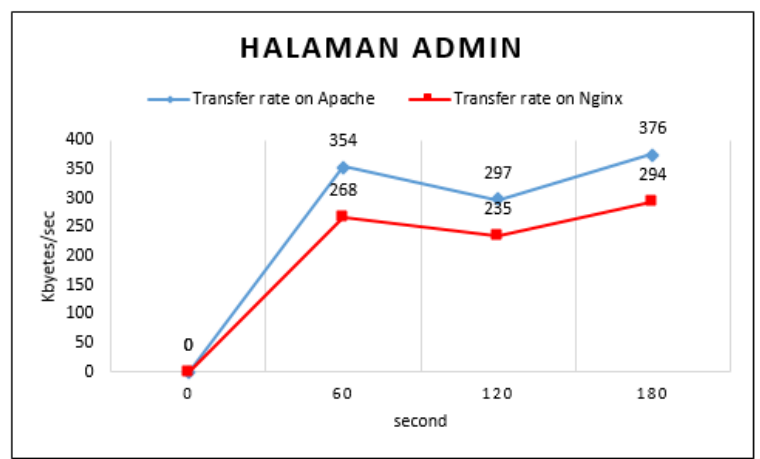

Gambar 5. Grafik Pengujian Halaman Admin Login - Transfer Rate

Pada Gambar 5 grafik yang dihasilkan dari pengujian halaman admin yang dilakukan sebanyak 3 kali percobaan pada variable transfer rate. Hasil pengujian halaman category seperti pada Tabel 3.

TABEL 3. PENGUJIAN HALAMAN CATEGORY

\begin{tabular}{|c|c|c|c|c|}
\hline No & Variable & Percobaan 1 & Percobaan & Percobaan 3 \\
\hline 1 & $\begin{array}{l}\text { Time per } \\
\text { Request on } \\
\text { Apache }\end{array}$ & & $\begin{array}{c}533.910= \\
534(\mathrm{~ms})\end{array}$ & $\begin{array}{c}512.826= \\
513(\mathrm{~ms})\end{array}$ \\
\hline 2 & $\begin{array}{l}\text { Time per } \\
\text { Request on } \\
\text { Nginx }\end{array}$ & & $\begin{array}{c}715.515= \\
715(\mathrm{~ms})\end{array}$ & $\begin{array}{c}687.647= \\
688(\mathrm{~ms})\end{array}$ \\
\hline 3 & $\begin{array}{l}\text { Connectior } \\
\text { Times on } \\
\text { Apache }\end{array}$ & (ms) & $530(\mathrm{~ms})$ & $511(\mathrm{~ms})$ \\
\hline 4 & $\begin{array}{l}\text { Connection } \\
\text { Times on } \\
\text { Nginx }\end{array}$ & $648(\mathrm{~ms})$ & $712(\mathrm{~ms})$ & $\begin{array}{l}683 \\
(m s)\end{array}$ \\
\hline 5 & $\begin{array}{l}\text { Transfer Rate } \\
\text { on Apache }\end{array}$ & $\begin{array}{c}773.83 \\
=774 \\
(\text { Kbyetes } / \text { s) } \\
\end{array}$ & $\begin{array}{c}699.34=699 \\
(\text { Kbyetes } / s)\end{array}$ & $\begin{array}{c}729.95= \\
730 \\
\text { (Kbyetes } / \text { s) }\end{array}$ \\
\hline 6 & $\begin{array}{l}\text { Transfer Rate } \\
\text { on Nginx }\end{array}$ & $\begin{array}{c}573.29 \\
=573 \\
(\text { Kbyetes } / \text { s) }\end{array}$ & $\begin{array}{c}520.47=520 \\
(\text { Kbyetes } / s)\end{array}$ & $\begin{array}{c}543.36= \\
543 \\
\text { (Kbyetes } / s)\end{array}$ \\
\hline
\end{tabular}

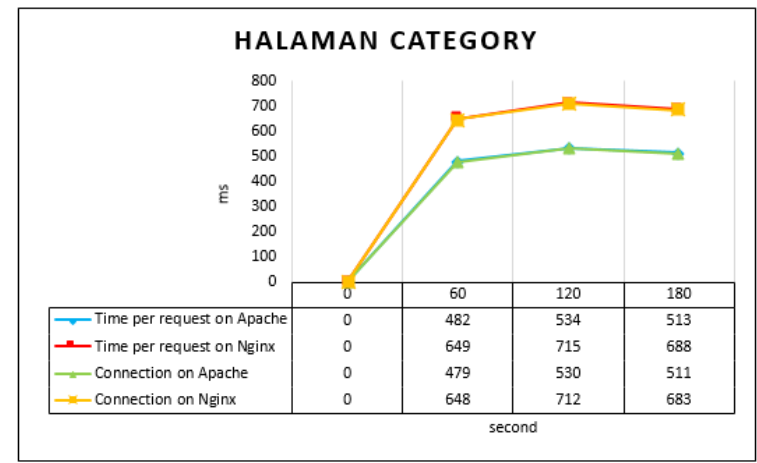

Gambar 6. Grafik Pengujian Halaman Category

Pada Gambar 6 grafik yang didapatkan dari halaman category pada pengujian web server pada variabel time per request dan connection.

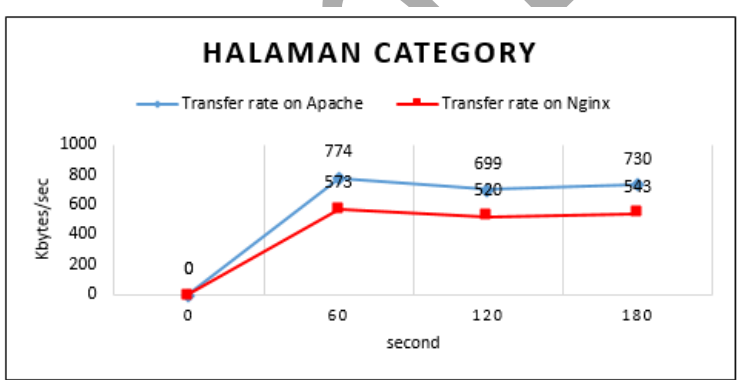

Gambar 7. Grafik Halaman Category - Transfer Rate

Pada Gambar 7 grafik yang didapatkan dari halaman category pada pengujian web server pada variable transfer rate. Hasil pengujian halaman authentication ditunjukkan pada Tabel 4.

\begin{tabular}{|c|c|c|c|c|}
\hline No & Variable & $\begin{array}{c}\text { Percobaan } \\
1\end{array}$ & $\begin{array}{c}\text { Percobaan } \\
2\end{array}$ & Percobaan 3 \\
\hline 1 & $\begin{array}{l}\text { Time per } \\
\text { Request on } \\
\text { Apache }\end{array}$ & $\begin{array}{l}474.366= \\
474(\mathrm{~ms})\end{array}$ & $\begin{array}{l}522.754= \\
523(\mathrm{~ms})\end{array}$ & $\begin{array}{l}514.894= \\
515(\mathrm{~ms})\end{array}$ \\
\hline 2 & $\begin{array}{l}\text { Time per } \\
\text { Request on } \\
\text { Nginx }\end{array}$ & $\begin{array}{l}675.777= \\
676(\mathrm{~ms})\end{array}$ & $\begin{array}{l}707.143= \\
707(\mathrm{~ms})\end{array}=$ & $\begin{array}{l}676.734= \\
677(\mathrm{~ms})\end{array}$ \\
\hline 3 & $\begin{array}{l}\text { Connection } \\
\text { Times on } \\
\text { Apache }\end{array}$ & 472 (ms) & $521(\mathrm{~ms})$ & $512(\mathrm{~ms})$ \\
\hline 4 & $\begin{array}{l}\text { Connection } \\
\text { Times on } \\
\text { Nginx }\end{array}$ & $672(\mathrm{~ms})$ & $704(\mathrm{~ms})$ & 671 (ms) \\
\hline 5 & $\begin{array}{l}\text { Transfer } \\
\text { Rate on } \\
\text { Apache }\end{array}$ & $\begin{array}{l}771.70= \\
772 \\
(\text { Kbyetes } / s)\end{array}$ & $\begin{array}{l}702.98 \\
=703 \\
(\text { Kbyetes } / \text { s) }\end{array}$ & $\begin{array}{l}716.12= \\
716 \\
(\text { Kbyetes } / \text { s) }\end{array}$ \\
\hline 6 & $\begin{array}{l}\text { Transfer } \\
\text { Rate on } \\
\text { Nginx }\end{array}$ & $\begin{array}{l}539.91= \\
540 \\
\text { (Kbyetes/se } \\
\text { c) }\end{array}$ & $\begin{array}{l}516.15 \\
=516 \\
(\text { Kbyetes } / \mathrm{s})\end{array}$ & $\begin{array}{l}539.35= \\
539 \\
\text { (Kbyetes } / s)\end{array}$ \\
\hline
\end{tabular}




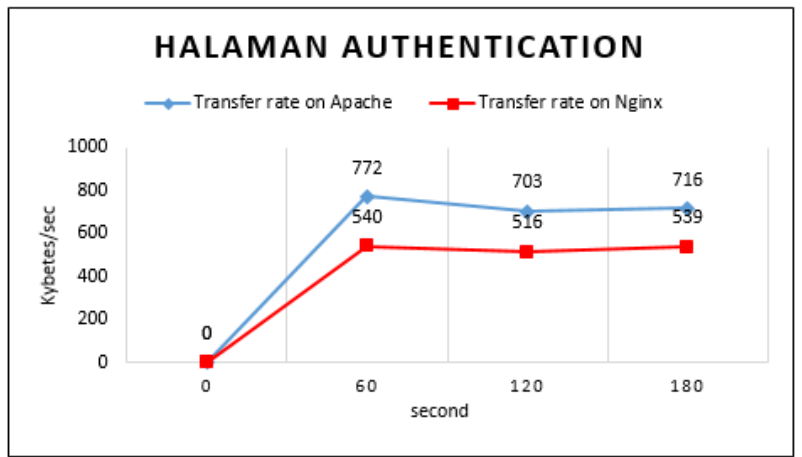

Gambar 8. Grafik Pengujian Halaman AuthenticationTransfer Rate

Pada Gambar 8 grafik di atas menjelaskan nilai dari hasil pengujian authentication yang didapatkan dari pengujian transfer rate.

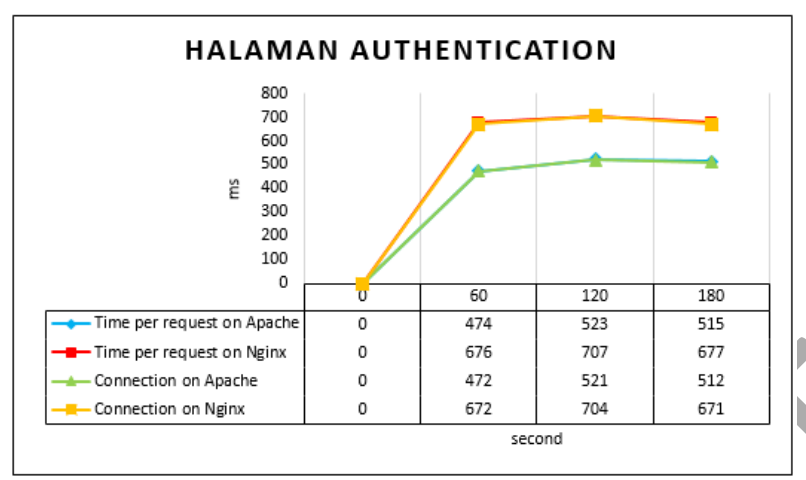

Gambar 9. Grafik Pengujian Halaman Authentication

Pada Gambar 9 grafik di atas menjelaskan nilai dari hasil pengujian authentication yang didapatkan dengan 3 kali pengujian. Hasil pengujian halaman price seperti pada Tabel 5.

TABEL 5. PENGUJIAN HALAMAN PRICE

\begin{tabular}{|c|c|c|c|c|}
\hline No & Variable & Percobaar & $\begin{array}{c}\text { Percobaan } \\
2\end{array}$ & $\begin{array}{c}\text { Percobaan } \\
3\end{array}$ \\
\hline 1 & $\begin{array}{l}\text { Time per } \\
\text { Request on } \\
\text { Apache }\end{array}$ & & $\begin{array}{l}583.658= \\
584(\mathrm{~ms})\end{array}$ & $\begin{array}{l}554.105= \\
554(\mathrm{~ms})\end{array}$ \\
\hline 2 & $\begin{array}{l}\text { Time per } \\
\text { Request on } \\
\text { Nginx }\end{array}$ & & $\begin{array}{l}706.432= \\
706(\mathrm{~ms})\end{array}$ & $\begin{array}{l}702.671= \\
703(\mathrm{~ms})\end{array}$ \\
\hline 3 & $\begin{array}{l}\text { Connection } \\
\text { Times on } \\
\text { Apache }\end{array}$ & $(\mathrm{ms})^{564}$ & $583(\mathrm{~ms})$ & $(m s)^{550}$ \\
\hline 4 & $\begin{array}{l}\text { Connection } \\
\text { Times on } \\
\text { Nginx }\end{array}$ & $(m s)^{725}$ & $(m s)^{702}$ & $(\mathrm{~ms})^{700}$ \\
\hline 5 & $\begin{array}{l}\text { Transfer } \\
\text { Rate on } \\
\text { Apache }\end{array}$ & $\begin{array}{l}659.82= \\
660 \\
(\text { Kbyetes } / \text { s) } \\
\end{array}$ & $\begin{array}{l}637.79= \\
638 \\
\text { (Kbyetes } / \text { s) }\end{array}$ & $\begin{array}{l}671.82= \\
672 \\
(\text { Kbyetes } / \text { s) }\end{array}$ \\
\hline 6 & $\begin{array}{l}\text { Transfer } \\
\text { Rate on } \\
\text { Nginx }\end{array}$ & $\begin{array}{l}509.76= \\
510 \\
\text { (Kbyetes } / \text { s) }\end{array}$ & $\begin{array}{l}525.25= \\
525 \\
(\text { Kbyetes } / s)\end{array}$ & $\begin{array}{l}528.08= \\
528 \\
(\text { Kbyetes } / s)\end{array}$ \\
\hline
\end{tabular}

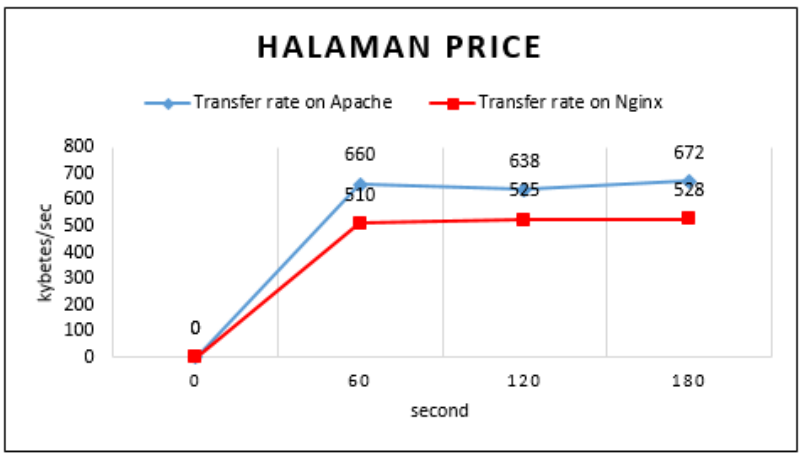

Gambar 10. Grafik Pengujian Halaman Price - Transfer Rate

Pada Gambar 10 grafik pengujian halaman price yang pengujiannya beracuan pada variable transfer rate.

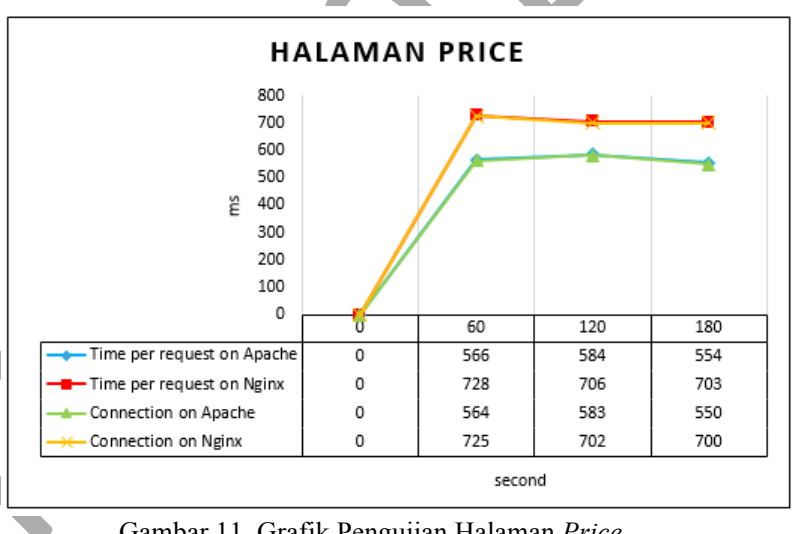

Gambar 11. Grafik Pengujian Halaman Price

Pada Gambar 11 grafik menjelaskan hasil yang didapat dari pengujian web server, angka yang ditampilkan sudah dibulatkan sebelumnya.

\section{Evaluasi hasil pengujian}

Evaluasi hasil pengujian kecepatan perfomance dari kedua web server dari segi time per request Apache lebih unggul dari pada Nginx karena kecepatan request dari Apache lebih cepat dibandingkan dengan Nginx, itu terbukti dengan lebih kecilnya angka yang keluar dari Apache server. Bisa dikatakan semakin kecil angka yang dihasilkan semakin cepat proses request. Selain itu hasil proses request dari Apache lebih banyak dibandingkan Nginx.

Connection times web server Apache lebih baik dengan nilai rata-rata per millisecond yang kecil, sehingga koneksi yang dilakukan user ketika membuka situs website yang berada di web server Apache stabil. Sedangkan connection times web server Nginx nilai rata-rata yang dihasilkan lebih besar dibandingkan dengan Apache.

Dan terakhir dari segi transfer rate pada Apache memiliki nilai transfer yang cukup tinggi, sehingga proses transfer data atau files yang dilakukan di web server Apache lebih cepat. 
Sebaliknya transfer rate yang dihasilkan Nginx lebih rendah dibandingan dengan Apache, sehingga proses transfer data sedikit lambat.

\section{KESIMPULAN}

Berdasarkan hasil penelitian kami dengan judul Analisis Web server Untuk Pengembangan Hosting Server Institusi, dan sub judul pembandingan kinerja web server Apache dengan web server Nginx, dapat disimpulkan bahwa :

Analisa kinerja dari kedua web server dengan parameter transfer rate, time per request, dan connection time sebagai indikator pengukuran untuk pengujian kinerja dari kedua web server. Dan metode pengujian menggunakan proses benchmark didapatkan hasil bahwa transfer rate pada web server Apache adalah 949 Kbytes/sec, 354 Kbytes/sec, 774 Kbytes/sec, 772 Kbytes/sec, 660 Kbytes/sec dan web server Nginx $=720$ Kbytes/sec, $268 \mathrm{Kbytes} / \mathrm{sec}, 573 \mathrm{Kbytes} / \mathrm{sec}, 540 \mathrm{Kbytes} / \mathrm{sec}$, $510 \mathrm{Kbytes} / \mathrm{sec}$. Time per request pada web server Apache $=395 \mathrm{~ms}, 137 \mathrm{~ms}, 482 \mathrm{~ms}, 474 \mathrm{~ms}, 566 \mathrm{~ms}$. Dan pada web server Nginx $=516 \mathrm{~ms}, 180 \mathrm{~ms}, 649$ $\mathrm{ms}, 676 \mathrm{~ms}, 728 \mathrm{~ms}$. connection time pada web server Apache $=393 \mathrm{~ms}, 137 \mathrm{~ms}, 479 \mathrm{~ms}, 472 \mathrm{~ms}$, $564 \mathrm{~ms}$ dan web server Nginx $=513 \mathrm{~ms}, 180 \mathrm{~ms}$, $648 \mathrm{~ms}, 672 \mathrm{~ms}, 725 \mathrm{~ms}$.

Kesimpulan analisis dari hasil pengujian tersebut ditemukan web server Apache memiliki kinerja lebih baik dari pada web server Nginx, dimana kemungkinan pengguna web server Apache belum mengetahui. Hal tersebut bahwa web server Apache memiliki kecepatan transfer rate, time per request dan connection time lebih cepat dibandingkan dengan Nginx, dimana dengan nilai transfer rata-rata dari Apache 701 Kbytes/sec sedangkan Nginx 522 Kbytes/sec.

Kritik dan saran dari hasil penelitian ini dapat dikaji beberapa hal dalam melaksanakan pengembangan penggunaan web server agar menjadi bahan evaluasi sehingga penerapan pada institusi menjadi lebih baik. Kritik dan saran adalah sebagai berikut :

1. Pada sistem hosting server ini khususnya pada web server memfokuskan pada pembahasan mengenai pengujian kecepatan transfer data, waktu request dan koneksi saja dan belum memerhatikan aspek lainnya. Oleh karena itu peneliti menyarankan agar sistem ini dapat dikembangkan kembali dimasa yang akan datang.

2. Dalam proses hosting server Infrastruktur jaringan institusi, web server yang digunakan disesuaikan dengan kebutuhan, dilihat dari kelebihan dan kekurangan masing-masing web server.
3. Melakukan maintenance secara berkala yang bertujuan untuk menjaga kinerja hosting server, dan menjaga keamanan hosting server dari serangan hacking dan lain lain.

\section{REFERENSI}

[1] Xiuquan Qiao, Guoshun Nan, Wei Tan, Lei Guo, Junliang Chen, Wei Quan, Yukai Tu, "CCNxTomcat: An extended web server for Content-Centric Networking”, Computer Networks, Volume 75, Part A, 24 December 2014, Pages 276-296.

[2] Andre Felipe Monteiro, Marcus Vinicius Azevedo, Alexandre Sztajnberg, "Virtualized Web server cluster selfconfiguration to optimize resource and power use”, Journal of Systems and Software, Volume 86, Issue 11, November 2013, Pages 2779-2796.

[3] Sopandi, Dede, Instalasi dan Konfigurasi Jaringan Komputer, Penerbit Informatika, Bandung, 2010.

[4] Apache Web Server Complete Guide, Dedoimedo www.dedoimedo.com

[5] Abdullah, Dahlan, "Perancangan dan Implementasi Virtual Hosting Menggunakan Linux”. Jurnal Penelitian Teknik Informatika Universitas Malikussaleh, Lhokseumawe, Aceh, 2013.

[6] Dwiyankuntoko, Arsyad, Protokol SSL dan TLS. Jakarta, 2013

[7] Simarmata, Janner, "Rekayasa Web : Analisa dan Desain Sistem, Rekayasa Informasi, Rekayasa Kebutuhan, Data Mining, Manajemen Proyek”, ANDI OFFSET, Yogyakarta, 2010.

[8] Clément Nedelcu, Nginx HTTP Server, Packt Publishing, Birmingham, UK, ISBN 978-1-849510-86-8, 2010.

[9] Xiaoni Chi; Bichuan Liu; Qi Niu; Qiuxuan Wu, “Web Load Balance and Cache Optimization Design Based Nginx under High-Concurrency Environment.". Third International Conference on Digital Manufacturing \& Automation, 2012 Pages: $1029-1032$.

[10] Sverdlov, Etel, https://www.digitalocean.com/ community/ tutorials/how-to-install-linux-nginx-mysql-php-lemp-stackon-ubuntu-12-04, 2012. [20 Mei 2015].

[11] Sokam, Apache vs Nginx, http://sokam.or.id/log/ 592/apache-vs-nginx, 08 Mei 2014 